\title{
ESTUDO PARA INOVAR MÉTODOS EDUCACIONAIS COM COMPETÊNCIA DIGITAL
}

\author{
FLORIANÓPOLIS/SC MAIO/2018
}

\author{
Giovana Schueler - UFSC - giovanas@gmail.com \\ Fernando Spanhol - UFSC - profspanhol@gmail.com \\ Eleonora Falcão Vieira - UFSC - eleonorafalcao@gmail.com
}

Tipo: Investigação Científica (IC)

Natureza: Descrição de Projeto em Andamento

Categoria: Métodos e Tecnologias

Setor Educacional: EDUCAÇÃO SUPERIOR

\begin{abstract}
RESUMO
A atualização das práticas educacionais se tornou um desafio para a educação. Hoje em dia, buscase adequar as formas de ensinar em sala de aula e fora dela, visando atender ao perfil dos estudantes que possuem maior performance tecnológica. Nesse cenário, realiza-se um estudo focado em competências digitais tendo como objetivo o aperfeiçoamento de docentes. Para alcançar tal objetivo, faz-se uma pesquisa em cenário brasileiro e europeu sobre as competências digitais necessárias para a participação efetiva na sociedade moderna, agilizada e articulada em que vivemos. Em paralelo, realiza-se uma pesquisa local dentro da Universidade Federal de Santa Catarina, para levantar a situação de uso de tecnologias educacionais nos cursos de graduação e, assim, poder analisar o quanto a instituição e os docentes estão inovando as metodologias e processos de ensino. O estudo completo em andamento almeja propor formas e diretrizes para levar a UFSC à inovação, seguindo as instituições de ponta no contexto mundial. Com este artigo, pretende-se apresentar uma parte do estudo, que se destina à pesquisa da situação atual da universidade no que se refere à utilização das tecnologias em aulas e, ainda, apontar direcionamentos para a etapa de qualificação dos docentes quanto às competências digitais.
\end{abstract}

Palavras-chave: Competência digital. Tecnologias de Informação e comunicação. Metodologias de ensino. 


\section{1 - Introdução}

É perceptível a busca por inovação nos métodos educativos. Atualmente, instituições de ensino, professores e profissionais da educação estão envolvidos com ensino/aprendizagem estão à procura de aprimoramento nas formas de ensinar. Este fato ocorre dentro do cenário tecnológico em que vive a sociedade, no qual os estudantes têm uma infinidade de informações literalmente na palma da mão.

É possível aferir em artigos da área que não basta usar tecnologias em modelos antigos de ensinar. Para a geração atual de estudantes, é necessário repensar a atuação docente em sala de aula. Imagina-se que não haja tanta aceitação de uma aula expositiva de duas horas, se comparada a um vídeo dinâmico acessível na internet com a mesma abrangência de conteúdo, visto que o estudante pode conferir a mesma informação em um vídeo do YouTube, em dez minutos de pesquisa.

Para tal demanda, procura-se a intervenção das competências digitais nas instituições de ensino e na atuação dos professores, dentro e fora da sala a aula. Conforme Souza (2014, p. 1), "advogamos pela necessidade em discutir o desenvolvimento de Competências, especialmente, a Competência Digital dos professores.

Cabe ressaltar que a busca pelo aprimoramento e pela inovação dos docentes com competência digital de forma efetiva não é tarefa fácil, significa alcançar etapas de sedimentação das fases anteriores, entre elas, as citadas por Jordi Adell, em conferência em 2010: acesso, adoção, adaptação e apropriação. Essas etapas servem de base ao professor para chegar ao ponto da atuação inovadora, no qual se consegue propor novas formas para realizar estudos com a utilização de tecnologias digitais.

Nesse cenário, propõe-se o estudo que contribua com as pesquisas da área que venham ao encontro dos objetivos ansiados pelas instituições de ensino e de professores que querem se atualizar para atuar de forma eficiente com seus estudantes. O locus do estudo está na Universidade Federal de Santa Catarina (UFSC), sendo o foco professores atuam profissionalmente como docentes e pesquisadores.

A proposta do estudo prevê três etapas de trabalho, iniciando pelo levantamento e análise da utilização pelos professores da instituição, das tecnologias e de metodologias que levem à inovação nas formas de realizar aulas adequadas ao perfil dos estudantes "tecnológicos". Em um segundo momento, investigam-se modelos inovadores no cenário mundial, pesquisando práticas de docentes executadas com competências digitais e formas de gerenciar instituições para atuar no contexto de inovação das aulas, 
haja vista que a inovação vem também da forma de legislar da instituição que direciona a atuação docente. Em um terceiro momento do estudo, pretende-se trazer o resultado das etapas anteriores e, a partir das práticas atuais dos professores da UFSC e da forma de legislar desta instituição, comparar com as práticas de pesquisas das instituições mundiais inovadoras, para, por fim, fazer uma proposição de inovação na legislação da UFSC e na atuação dos seus docentes, tanto no ensino presencial quanto na modalidade a distância.

Neste artigo, objetiva-se apresentar a etapa primeira do estudo completo, focando-se, então, na busca da situação atual da UFSC quanto à utilização docente das tecnologias e de metodologias que levem à inovação, juntamente com o objetivo de mostrar como a instituição está organizada em sua legislação de direcionamento para atuação do corpo docente em suas metodologias de ensino.

\section{2 - Referencial teórico}

Considerando-se os desafios identificados em meio à sociedade tecnológica que estamos vivenciando, é importante analisar suas implicações no desenvolvimento de educação superior. Dessa forma, ressalta-se a existência das tecnologias de informação e comunicação (TICs). Nesse cenário, a "Educação é desafiada a ultrapassar o paradigma do ensino de conteúdos e a centrar-se no desenvolvimento de competências que possibilitem a aprendizagem ao longo da vida dos indivíduos" (BARBOSA; OSÓRIO, 2015, p. 1)

O Cenário educativo vem exigindo das instituições de ensino e dos docentes atualização nas formas de ensinar, mas essa situação não ocorre de forma simples. Conforme Souza e Souza (2014, p. 1): "Esse comportamento gerou situações pouco receptivas por parte dos professores que ecoam na percepção de atitudes negativas frente às novas tecnologias no espaço de aprendizagem como algumas pesquisas apresentam."

O desafio consiste em sensibilizar docentes a atualizar-se, deixar as amarras do modelo superado e conhecer as possibilidades inovadoras disponibilizadas pelas tecnologias contemporâneas.

Para isso, não basta impor novos modelos, é indispensável pensar na preparação do docente. Esse viés leva ao estudo das competências que o docente precisa adquirir, levando à necessidade de procurar a combinação de conhecimento, habilidades, atitudes e competências, apropriadas ao contexto, mais especificadamente, voltada à busca pela competência digital, uma das competências essências para a vivência do ser 
humano. Tema este que vem sendo amplamente estudado por instituições europeias, conforme mostra a European Commission (2010, p. 3), que contribui definindo as oito competências-chave para o desenvolvimento humano, sendo elas: comunicação na língua materna, comunicação em língua estrangeira, competência matemática e competências básicas em ciência e tecnologia, competência digital, aprender a aprender, competências sociais e cívicas, sentido de iniciativa e de empreendedorismo e consciência e expressão cultural. Entre tais competências, o foco deste estudo é a competência digital, que é definida por Lucas, Moreira e Costa (2017, p. 6) como:

[...] a utilização crítica e confiante das tecnologias da sociedade da informação para o trabalho, o lazer e a comunicação. Refere, ainda, que esta é sustentada pelas habilidades em TIC, mais concretamente pela utilização de computadores para recuperar, avaliar, armazenar, produzir, apresentar e trocar informação, e para comunicar e participar em redes de colaboração via internet.

Considera-se ainda fundamental abordar os marcos gerais da competência digital, para se chegar ao entendimento de como essa competência pode ser tratada no dia a dia na instituição e nas salas de aula. Trata-se de uma nova forma de trabalhar com um conjunto de elementos que resultam em inovação. Na Europa, o estudo sobre esses marcos se encontra em fase avançada, tanto que foi criado o Framework for Developing and Understanding Digital Competence in Europe (DIGCOMP), o qual propõe uma estrutura voltada à conquista de competência digital para todos os cidadãos. Conforme cita o Instituto Nacional de Tecnologías Educativas y de Formación del Profesorado (2017), entre os marcos da DIGCOMP, estão os elementos mostrados na Figura 1.

Figura 1 - Elementos da competência digital, representada a seguir: 


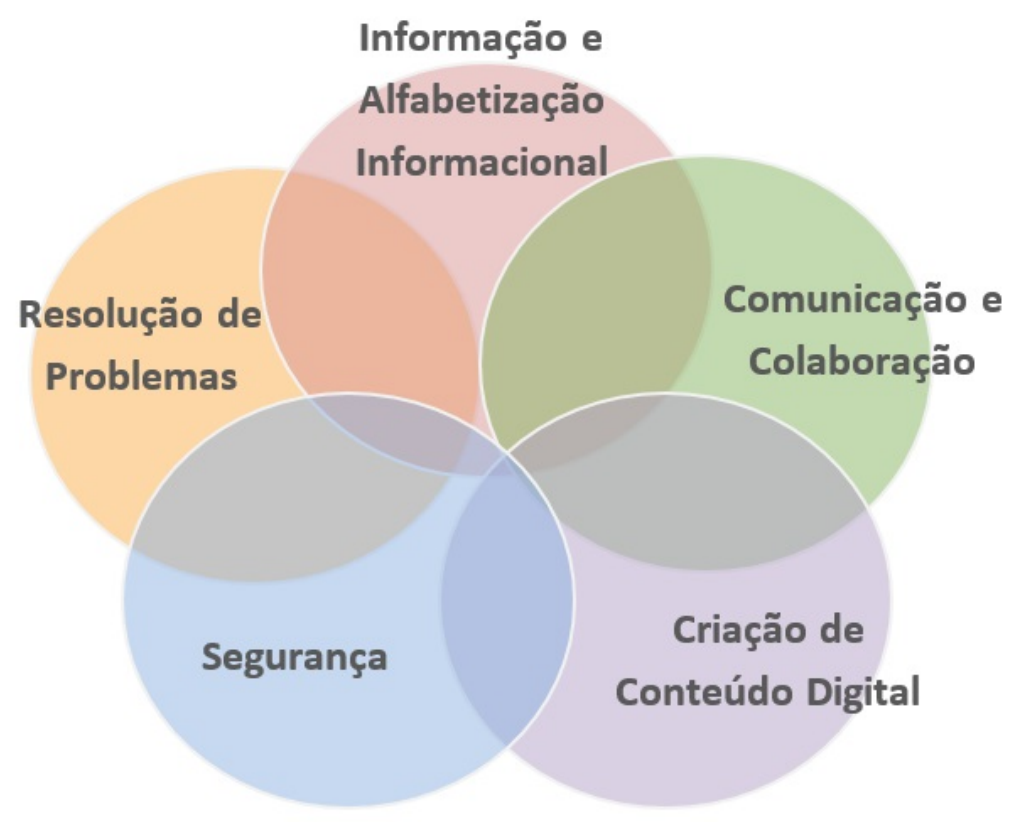

Fonte: Elaborada pelos autores com base em Instituto Nacional de Tecnologías Educativas y de Formación del Profesorado (2017, p. 7).

Essas perspectivas levam a novidades na forma de desenvolver o estudo. Conforme Aguaded (2016, p. 4): "Não poderíamos mais ter uma visão ingênua e romântica e pensar que a mídia transforma a escola; a escola precisa de professores vocacionados que acreditem em um mundo melhor."

É fundamental o entendimento de que, com as tecnologias digitais, professor e aluno possuem as mesmas chances de potencializar o processo de aprendizagem, e essa possibilidade dever ser entendida pelo professor como meio de conquista de novos conhecimentos em grupo. Dentro desse formato, conforme coloca Fernandes (2015, p. 24), o professor deixa de ser o foco no ensino para tornar-se mediador, orientador e facilitador do acesso, exploração, seleção e disseminação das informações obtidas via tecnologias de maneira ética e segura.

Nesse contexto, seguem-se os principais desafios preconizados pela atual sociedade do conhecimento, a investigação visa perspectivar as implicações das novas tecnologias no ensino superior e, especificamente, nas competências profissionais docentes.

É importante, ainda, salientar que essa parte da pesquisa está voltada ao professor, mas não isenta a instituição de ensino a reorganizar sua gestão e sua normatização no direcionamento do trabalho docente, assunto este que será trabalhado nos próximos 
passos da pesquisa completa.

\section{3 - Procedimento metodológico}

Para desenvolver a primeira parte do estudo, objeto de discussão deste artigo, buscaram-se, dentro da Universidade Federal de Santa Catarina, meios para levantar informações de como os professores estão trabalhando em sala de aula ou como estão utilizando novas tecnologias e metodologias de trabalho. Assim, procurou-se a Comissão Própria de Avaliação (CPA) da UFSC, setor que centraliza todas as avaliações de cursos em todos os centros da Universidade. Nesse setor, foi possível visualizar o Relatório de Avaliação de Curso de Graduação, em seu último relatório fechado, que corresponde à avaliação aplicada em 2016/2, no qual consta o resultado de avaliação da qualidade dos 114 cursos de graduação que compõem os 15 centros de ensino dessa instituição. O setor CPA aplica aos estudantes de todos os cursos um questionário com 10 questões avaliando itens diversos relacionados à atuação do docente, entre eles: presencialidade, disponibilidade, domínio de conteúdo, coerência, estímulo, uso de técnicas e metodologias de ensino e, por fim, uso de tecnologias, sendo este último item representado pela seguinte questão: "7. O professor fez uso de diversificadas técnicas e metodologias de ensino, tais como: aulas expositivas, atividades, trabalhos em grupo, apresentações individuais e em grupo, seminários, fóruns e chats no Moodle, entre outras?" (UFSC, 2016, p. 9).

Com a tabulação e análise dos dados, foi possível encontrar alguns resultados importantes, conforme mostrado a seguir.

\section{4 - Apresentação dos resultados}

Para a averiguação dos resultados, primeiramente levantaram-se os números de totalização das respostas por centro de ensino da universidade. Para isso, fez-se uma média das avaliações gerais de todos os cursos ofertados. Os critérios de resultados seguem a lógica de pontuação de 1 a 5 , sendo 1 a pior avaliação e 5 a melhor. Nesses dados, encontramos cursos que se mantiveram na média e cursos com resultados negativos, se comparados aos outros e cursos com resultado positivo, conforme podese observar no Gráfico 1.

Gráfico 1 - Uso de tecnologias e metodologias diversificadas 


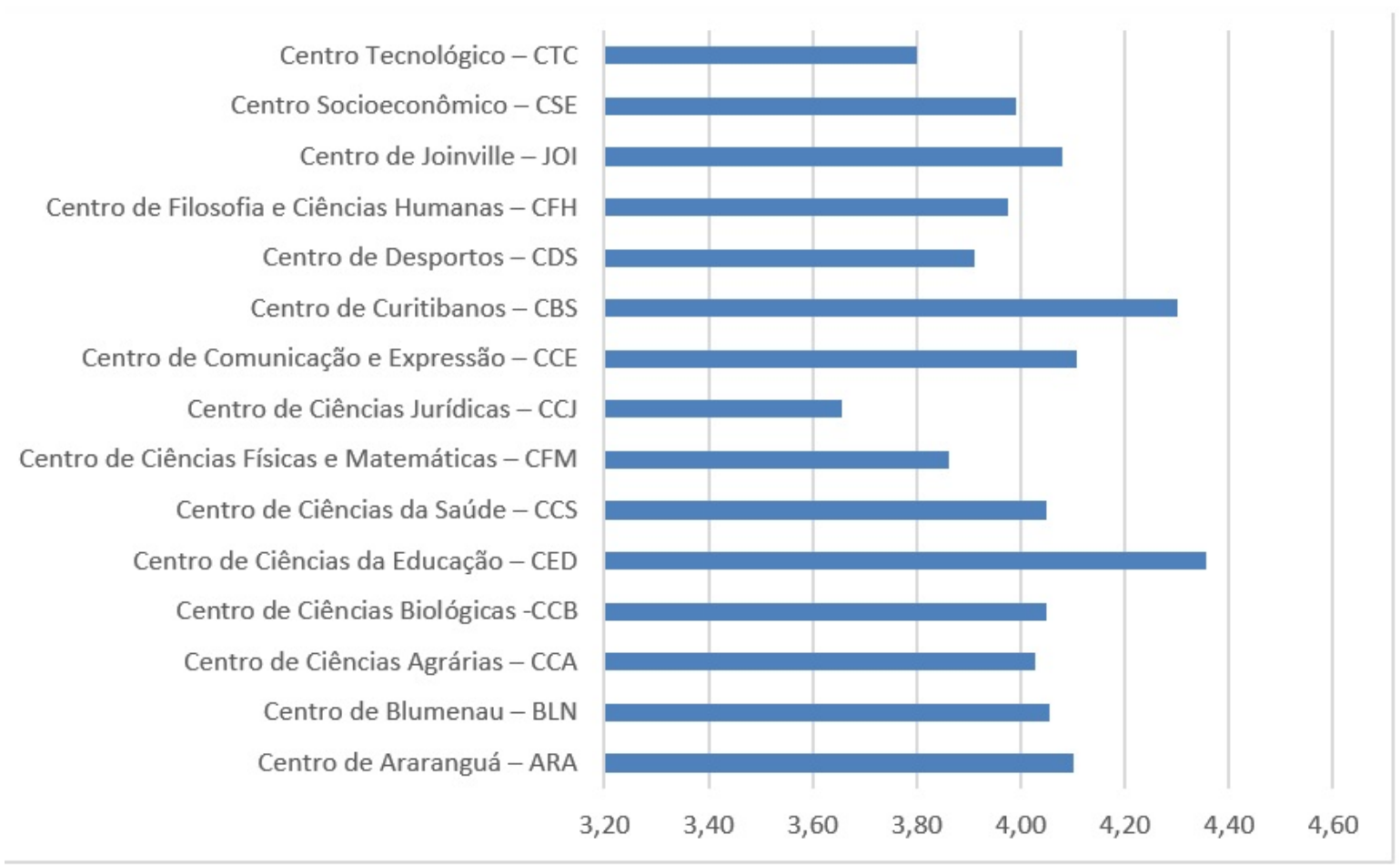

Fonte: Elaborado pelos autores (2018).

Após contabilizar os resultados, pôde-se observar que dois centros se destacaram e obtiveram melhores resultados quanto ao uso de tecnologias e diversidade de técnicas e metodologias de ensino. Um deles foi o Centro de Ciências da Educação (CED), cuja média geral dos cursos obteve o resultado de 4,4. Este centro situa-se no campus principal da UFSC, em Florianópolis, e possui os cursos de Arquivologia, Biblioteconomia, Educação do Campo e Pedagogia.

O segundo destaque foi o Centro de Curitibanos (CBS), com média geral de 4,3. Esse centro situa-se na cidade de Curitibanos, a 308 quilômetros do campus central em Florianópolis, e possui os cursos de Agronomia, Ciências Rurais, Engenharia Florestal e Medicina Veterinária.

Outros centros que se destacaram foram: Centro de Joinville, Centro de Comunicação e Expressão e Centro de Araranguá. Esses resultados analisados de forma breve já evidenciam que os campus situados fora da sede central possuem mais diversidade de técnicas e metodologias de ensino e usam mais tecnologias em sala de aula.

Outro ponto contabilizado na pesquisa foi avaliar se existe disparidades entre os cursos em relação ao seu centro. Para isso, levantou-se o curso com a média mais alta dentro de cada centro. Assim, pode-se observar que os centros não têm padronização em seus 
cursos (Gráfico 2).

Gráfico 2 - Cursos que se destacaram em cada centro.
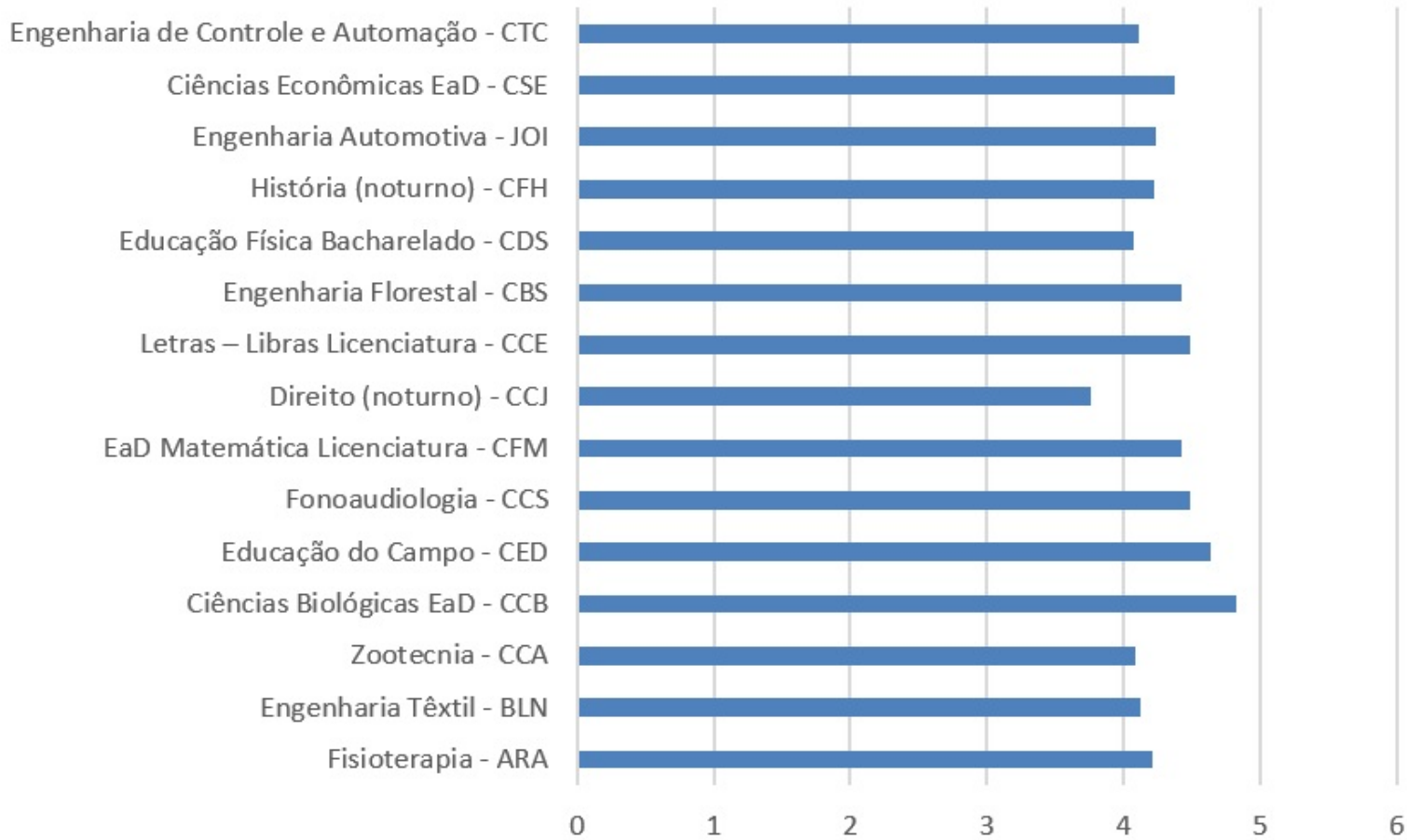

Fonte: Elaborado pelos autores (2018).

Ao analisar o resultado do gráfico, observou-se um fato interessante: entre os 5 cursos mais bem avaliados, somente 2 deles fazem parte dos centros com melhores resultados. Curiosamente, o curso de Ciências Biológicas EaD teve melhor resultado, com média de 4,82, e não está entre os centros com melhor avaliação. Na sequência de colocação, estão os seguintes cursos: Educação do Campo, Letras - Libras Licenciatura, Fonoaudiologia e Ciências Econômicas EaD. Entre os outros cursos em destaque, estão Ciências Biológicas e Economia, ambos ofertados na modalidade EaD. Cogita-se que o destaque se dê pelas características da modalidade de estudo mediado por tecnologias de informação e comunicação.

De todo modo, constata-se a disparidade entre as formas de atuação docente em cursos que se destacam em centros que não têm melhores resultados. Entende-se que o mérito ou a busca por capacitação em competências digitais vem de movimentos individuais dos docentes que buscam melhores e novas formas de ensinar.

\section{5 - Conclusões}


Com o desenvolvimento de estudo no sentido macro e da realização da etapa inicial focada no levantamento da atuação dos docentes da UFSC quanto à utilização das tecnologias e de metodologias que levem à inovação, percebeu-se a existência de disparidade entre os centros de estudo dessa instituição.

Observou-se a necessidade de uniformização das metodologias de ensino utilizadas por professores. A disparidade entre os níveis de avaliação e forma de trabalho nos cursos do mesmo centro corroboram a necessidade de investimentos em capacitações para preparar professores e equipes dos cursos para o uso de tecnologias e inovação nas técnicas e metodologias de estudo.

Quando se reflete sobre melhorias na atuação docente, está se pensando em competências digitais, abordando mais do que o uso básico de tecnologias, mas, sim, 0 aprendizado que incorpora as TICs como instrumento crucial de trabalho, em que o docente se sinta seguro, à vontade para inovar. E a partir desse amadurecimento, chegue ao almejado nível de criar práticas de ensino, agregando a inovação as aulas, e estas motivem, desafiem e conquistem os estudantes desta era do conhecimento, ágil e versátil que vivemos.

\section{6 - Referências}

ADELL, J. La competência Digital. 2010. 1 vídeo (1h34min). Disponível em: <http://www.youtube.com/watch?v=2azt48U27/Y>. Acesso em: 14 abr. 2018.

AGUADED, Ignacio. Precisamos de uma revolução educomunicativa para transformar o mundo. Revista Comunicação \& Educação, São Paulo, ano 21, n. 2, p. 97-101, jul./dez. 2016. Entrevista concedida à Revista. Disponível em: $<$ https://www.revistas.usp.br/comueduc/article/download/122602/120953>. Acesso em: 22 abr. 2018.

BARBOSA. Elaine Cristina de Andrade; OSÓRIO, António José Meneses. Competências digitais e desenvolvimento profissional de professores em rede: The Voice of the European. In: SIMPÓSIO HIPERTEXTO E TECNOLOGIAS DIGITAIS NA EDUCAÇÃO, 6 2015.

Disponível

em:

$<$ http://www.nehte.com.br/simposio/anais/Anais-

Hipertexto-2015/Competencias\%20DG.pdf>. Acesso em: 22 abr. 2018.

EUROPEAN COMISSION. A Digital Agenda for Europe, 2010. Bruxelas, 2010. Disponível em: $<$ http://eur-lex.europa.eu/legal- 
content/EN/TXT/PDF/?uri=CELEX:52010DC0245R(01)\&from=EM>. Acesso em: 22 abr. de 2018.

FERNANDES, Mara Onilda Moura. Competências em tecnologias digitais na educação superior no Brasil e em Portugal. 2015. $214 \mathrm{f}$. Tese (Doutorado em Educação) - Programa de Pós-graduação em Educação, Universidade Federal da Paraíba, João Pessoa, 2015.2 Disponível em: $<$ http://tede.biblioteca.ufpb.br/handle/tede/8488>. Acesso em: 22 abr. 2018.

INSTITUTO NACIONAL DE TECNOLOGÍAS EDUCATIVAS Y DE FORMACIÓN DEL PROFESORADO. Marco Común de Competencia Digital Docente. Madri, 2017. Disponível em: $<$ http://educalab.es/documents/10180/12809/MarcoComunCompeDigiDoceV2.pdf>. Acesso em: 22 abr. 2018.

SOUZA E SOUZA, Liz Sandra Souza. Análise do desenvolvimento da Competência Digital: uma contribuição para formação docente. In: ASSOCIAÇÃO NACIONAL DE PÓS-GRADUAÇÃO E PESQUISA EM EDUCAÇÃO, 2014. Disponível em: $<$

http://www.fe.ufg.br/nedesc/cmv/controle/DocumentoControle.php?oper=download\&cod= 1582>. Acesso em: 14 abr. 2018.

UNIVERSIDADE FEDERAL DE SANTA CATARINA (UFSC). Relatório de avaliação de curso semestre 2016/1. Florianópolis: UFSC, 2018. Disponível em: $<$ http://cpa.ufsc.br/files/2016/10/Relat\%C3\%B3rio-de-curso-2016.11.pdf>. Acesso em 22 abr. 2018. 